\title{
Research
}

\section{Variation in use of the 2-week referral pathway for suspected cancer:}

\author{
a cross-sectional analysis
}

\begin{abstract}
Background

A 2-Week Wait (2WW) referral pathway for earlier diagnosis of suspected cancer was introduced in England in 2000. Nevertheless, a significant proportion of patients with cancer are diagnosed by other routes (detection rate), only a small proportion of 2WW referrals have cancer (conversion rate) and there is considerable between-practice variation.

\section{Aim}

This study examined use by practices of the $2 \mathrm{WW}$ referral in relation to all cancer diagnoses.
\end{abstract}

\section{Design and setting}

A cross-sectional analysis of data extracted from the Cancer Waiting Times Database for all 2WW referrals in 2009 and for all patients receiving a first definitive treatment in the same year

\section{Method}

The age standardised referral ratio, conversion rate, and detection rate were calculated for all practices in England and the correlation coefficient for each pair of measures. The median detection rate was calculated for each decile of practices ranked by conversion rate and vice versa, performing nonparametric tests for trend in each case.

\section{Results}

Data for 8049 practices, 865494 referrals, and 224984 cancers were analysed. There were significant correlations between referral ratio and conversion rate (inverse) and detection rate (direct). There was also a direct correlation between conversion and detection rates. There was a significant trend in conversion rate for deciles of detection rate, and vice versa, with a marked difference between the lowest and higher deciles.

\section{Conclusion}

There is a consistent relationship between $2 \mathrm{WW}$ referral conversion rate and detection rate that can be interpreted as representing quality of clinical practice. The $2 \mathrm{WW}$ referral rate should not be a measure of quality of clinical care.

\section{Keywords}

cancer diagnosis; quality of care; primary care; referral.

\section{INTRODUCTION}

Achieving earlier diagnosis of cancer has been a part of the strategy for improving cancer outcomes in England since 2000, when an urgent GP referral pathway for suspected cancer, requiring that patients should wait no more than 2 weeks to be seen (here termed a 2-Week Wait (2WW) referral) was introduced." The Cancer Reform Strategy ${ }^{2}$ identified early diagnosis as being critical to improved survival, a priority recently reiterated in Improving Outcomes: a Strategy for Cancer. ${ }^{3}$ It led to the National Awareness and Early Diagnosis Initiative, ${ }^{4}$ a series of actions intended to understand and address the reasons for later diagnosis of cancer in England.

Implicit in the 2WW referral pathway in England is the intention that the majority of cancers should be diagnosed by this route, while efficient use of the pathway would be demonstrated by the precision of its use. As increasingly detailed data on 2WW referrals has become available at a national level, it is apparent that a significant proportion of cancers reach a diagnosis by other routes (in 2007 only $25 \%$ of cancers were diagnosed through the $2 \mathrm{WW}$ pathwayl, while the proportion of $2 \mathrm{WW}$ referrals found to have cancer has fallen from $13 \%$ in 2006 2007 to $11 \%$ in $2009-2010 .{ }^{6}$ The criteria for $2 \mathrm{WW}$ referral have long been considered to be too narrowly defined ${ }^{7}$ and there is wide variation in compliance with the guidelines for its use. ${ }^{8}$ Nevertheless, efficient referral

D Meechan, MSc, MPH, director; C Gildea, MSc, cancer intelligence analyst; L Hollingworth, BSc, information specialist, Trent Cancer Registry, Sheffield. MA Richards, MD, FRCP, National Cancer Director, National Cancer Action Team, London. D Riley, MSc, associate director, National Cancer Intelligence Network, London. G Rubin, FRCGP, FRCP(E), professor of general practice and primary care, Durham University, Stockton on Tees.

\section{Address for correspondence}

Greg Rubin, Durham University, School of practice, underpinned by NICE advice, ${ }^{9}$ is now a key part of the Quality, Innovation, Productivity and Prevention (QIPP) agenda for the NHS. ${ }^{10}$ Furthermore, fast-track referral for suspected cancer is being viewed as a valuable diagnostic option elsewhere in Europe as countries seek to improve their cancer survival statistics. ${ }^{11,12}$

More recently, the amount of variation in use of the $2 \mathrm{WW}$ pathway between practices and primary care trusts has been a cause for concern for the National Audit Office and the Public Accounts Committee, ${ }^{13}$ both of which have recommended that this should be investigated and addressed by commissioners. Every practice in England can now access its cancer profile, a set of 24 measures relating to cancer screening and diagnosis, produced by the National Cancer Intelligence Network in December 2010, which includes data on $2 \mathrm{WW}$ referrals and is intended to support quality improvement in this area. ${ }^{14}$ The interpretation of these profiles, however, has been hampered by uncertainty among GPs and Cancer Networks as to what represents best practice.

This study examined use by practices of the $2 \mathrm{WW}$ referral pathway and related this to all cancer diagnoses on the Cancer Waiting Times Database (CWT-Db) to identify patterns of use that might represent good practice.

\section{Method}

Data, including patient's NHS number,

Medicine and Health, Wolfson Research Institute, Queen's Campus, University Boulevard, Stockton on Tees, TS17 6BH, UK.

E-mail: g.p.rubindadurham.ac.uk

Submitted: 29 January 2012; Editor's response:

14 February 2012; final acceptance: 10 April 2012 CBritish Journal of General Practice

This is the full-length article (published online 28 Aug 2012) of an abridged version published in print. Cite this article as: Br J Gen Pract 2012; DOI: 10.3399/bjgp12X654551. 


\section{How this fits in}

There is considerable variation in GP' use of the 2-week referral pathway for suspected cancer, in the proportion of those referrals that prove to have cancer (conversion rate) and in the proportion of all cancer diagnosed by this pathway (detection rate). This study shows a relationship between the latter two measures that represents quality of clinical practice and has potential as a quality indicator.

were extracted from the national CWT-Db for all $2 \mathrm{WW}$ referrals with a date first seen in 2009 and for all patients receiving a first definitive treatment for cancer lincluding, as well as conventional treatments, active monitoring and declined treatment) with a treatment start date in 2009.

The patient's registered GP practice las at mid-2010) and demographic information (including date of birth and postcode) were obtained by tracing patients lusing the NHS Open Exeter Batch Tracing Servicel according to their NHS number.

The age-standardised referral ratio, conversion rate, and detection rate were calculated for all practices in England, excluding those with a list size $<1000$ and those where different data sources indicated a considerable change in list size, suggesting practice mergers or closures.

The measures were calculated in accordance with the methodology used for producing practice cancer profiles ${ }^{15}$ and are defined as follows:

- Referral ratio - the indirectly standardised number of 2WW referrals relative to the GP list size.

- Conversion rate - the proportion of $2 \mathrm{WW}$ referrals which result in a cancer diagnosis (positive predictive value [PPV]).

- Detection rate - the proportion of cancers treated which were $2 \mathrm{WW}$ referrals (sensitivity).

Table 1. Referral, conversion, and detection rates, by various factors

\begin{tabular}{|c|c|c|c|c|c|c|c|}
\hline Factor & $\begin{array}{l}\text { Number of } \\
\text { PP practices }\end{array}$ & $\begin{array}{c}\text { Age-sex } \\
\text { standardised RR }\end{array}$ & $95 \% \mathrm{Cl}$ & CR & $95 \% \mathrm{Cl}$ & DR & $95 \% \mathrm{Cl}$ \\
\hline Total & 8049 & 100.00 & & 0.11 & (0.11 to 0.11$)$ & 0.43 & (0.43 to 0.43 ) \\
\hline$<65$ & 8049 & & & 0.07 & (0.07 to 0.07$)$ & 0.42 & (0.41 to 0.42 ) \\
\hline$\geq 65$ & 8048 & & & 0.17 & (0.17 to 0.17 ) & 0.44 & (0.46 to 0.44$)$ \\
\hline \multicolumn{8}{|l|}{ Practice deprivation } \\
\hline 2 & 1423 & 101.12 & $(100.67$ to 101.58$)$ & 0.12 & (0.11 to 0.12$)$ & 0.44 & (0.43 to 0.44$)$ \\
\hline 3 & 1513 & 103.59 & $(103.12$ to 104.06$)$ & 0.11 & (0.11 to 0.12$)$ & 0.44 & (0.44 to 0.44$)$ \\
\hline 4 & 1654 & 102.68 & 102.20 to 103.17$)$ & 0.11 & $(0.11$ to 0.11$)$ & 0.43 & (0.42 to 0.43 ) \\
\hline Most deprived & 2074 & 96.03 & (95.53 to 96.54 ) & 0.10 & (0.10 to 0.10$)$ & 0.40 & (0.39 to 0.40 ) \\
\hline \multicolumn{8}{|l|}{ SHA } \\
\hline North East & 380 & 113.60 & $(112.60$ to 114.60$)$ & 0.11 & (0.11 to 0.12 ) & 0.42 & (0.41 to 0.42 ) \\
\hline North West & 1243 & 101.81 & 101.23 to 102.39$)$ & 0.11 & (0.11 to 0.11$)$ & 0.42 & (0.42 to 0.43 ) \\
\hline East Midlands & 613 & 103.39 & 102.66 to 104.12$)$ & 0.12 & $(0.12$ to 0.12$)$ & 0.45 & (0.44 to 0.45 ) \\
\hline West Midlands & 934 & 105.42 & 104.75 to 106.09$)$ & 0.10 & $(0.10$ to 0.11$)$ & 0.43 & (0.42 to 0.44$)$ \\
\hline East of England & 776 & 98.31 & (97.69 to 98.93) & 0.11 & (0.11 to 0.12 ) & 0.42 & (0.42 to 0.43 ) \\
\hline London & 1478 & 89.35 & (88.80 to 89.90 ) & 0.09 & (0.09 to 0.09 ) & 0.38 & (0.37 to 0.39 ) \\
\hline South East Coast & 623 & 106.16 & 105.43 to 106.89$)$ & 0.10 & $(0.10$ to 0.11$)$ & 0.45 & (0.44 to 0.46 ) \\
\hline South Central & 497 & 93.64 & (92.91 to 94.37) & 0.12 & (0.12 to 0.12 ) & 0.47 & (0.46 to 0.47 ) \\
\hline South West & 716 & 105.20 & 104.55 to 105.86$)$ & 0.12 & $(0.12$ to 0.13$)$ & 0.45 & (0.46 to 0.46 ) \\
\hline \multicolumn{8}{|l|}{ Referral ratioa } \\
\hline High & 1949 & 147.06 & 146.59 to 147.54$)$ & 0.09 & (0.09 to 0.09 ) & 0.48 & (0.47 to 0.48$)$ \\
\hline Average & 3106 & 99.39 & (99.04 to 99.73) & 0.12 & (0.12 to 0.12 ) & 0.44 & (0.44 to 0.44 ) \\
\hline Low & 2994 & 61.09 & (60.81 to 61.37) & 0.14 & $(0.14$ to 0.15$)$ & 0.37 & (0.37 to 0.37 ) \\
\hline \multicolumn{8}{|l|}{ Practice list size } \\
\hline$>6000$ & 3920 & 104.12 & (103.87 to 104.37$)$ & 0.11 & (0.11 to 0.11$)$ & 0.44 & (0.44 to 0.44$)$ \\
\hline $3001-6000$ & 2555 & 94.35 & (93.89 to 94.80 ) & 0.11 & $(0.11$ to 0.11$)$ & 0.41 & (0.41 to 0.42 ) \\
\hline$\leq 3000$ & 1574 & 76.17 & (75.44 to 76.90 ) & 0.12 & (0.12 to 0.12 ) & 0.37 & (0.36 to 0.38 ) \\
\hline
\end{tabular}

a High and low groups include practices with a standardised referral ratio which is significantly higher or lower than 100. The average group includes all other practices. $C R=$ conversion rate. $D R=$ detection rate. $R R=$ referral ratio. $S H A=$ strategic health authority 


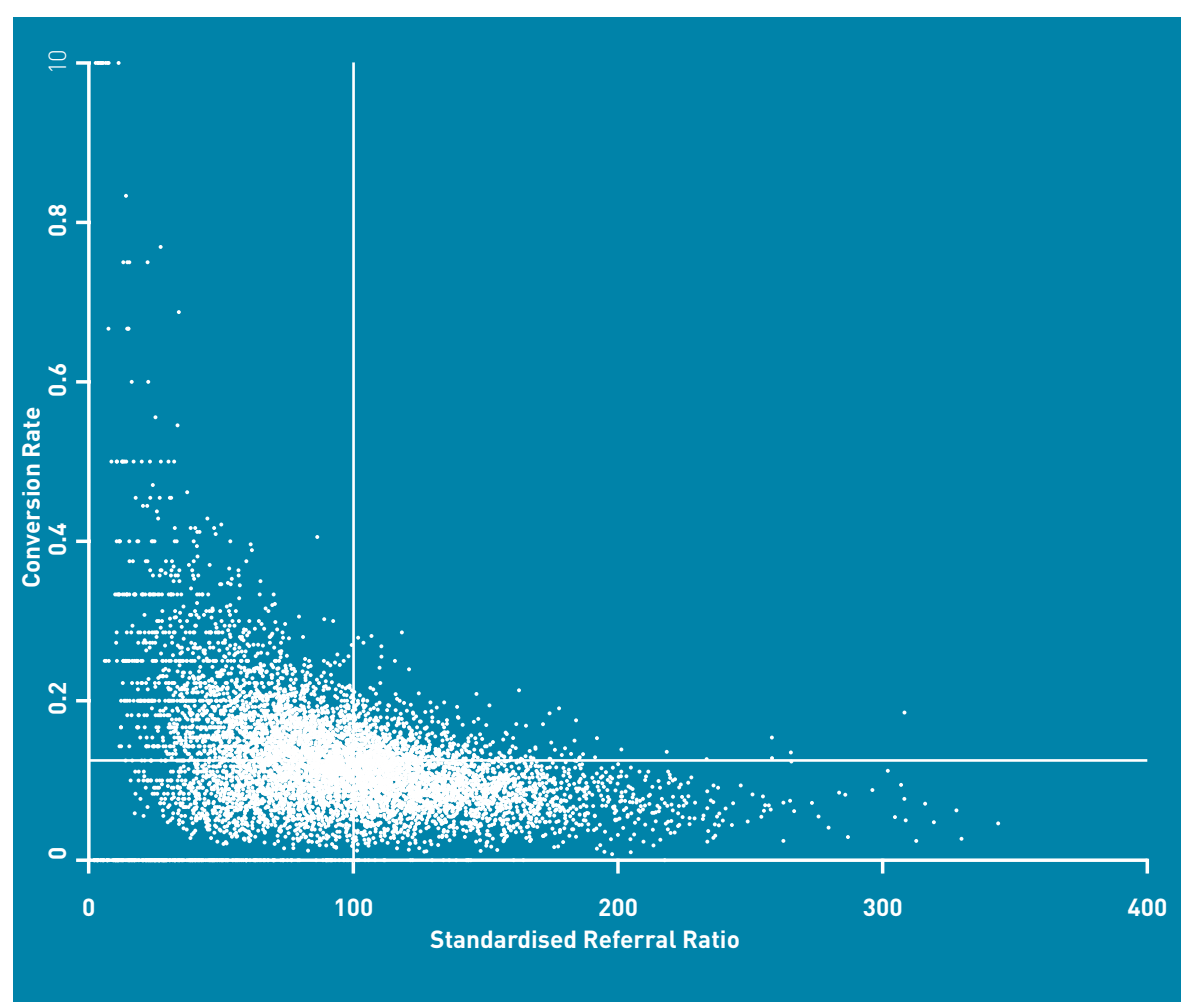

Figure 1. Correlation between age-sex standardised referral ratio and conversion rate.

Scatter plots were constructed and correlation coefficients were calculated for each of the three pairs of the three measures. As the rates are not normally distributed and the relationships are nonlinear, Spearman's rank correlation was used, which is based on the relative orders of the rates. The relationships between variables was also investigated for different patient and practice subgroups, based on patient's age $(<65$ and $\geq 65$ years), practice socioeconomic deprivation (IMD quintiles), ${ }^{16}$ practice list size, strategic health authority (SHA) and 2WW referral rates. The median detection rate was calculated also for each decile of practices ranked by conversion rate and the median conversion rate for each decile of practices ranked by detection rate. A nonparametric test for trend ${ }^{17}$ in detection rate was performed by deciles of conversion rate and vice versa. The analyses were performed using Stata (version 12).

\section{RESULTS}

Data on 865494 2WW referrals and 224984 cancers from 8049 of the 8229 practices in the 2008-2009 Quality and Outcomes Framework database were analysed.18 Table 1 shows the calculated referral, conversion and detection rates, overall and by patient and practice subgroups.

Of all $2 \mathrm{WW}$ referrals, $11 \%(n=96561)$ resulted in a cancer diagnosis (conversion rate). Diagnoses resulting from 2WW referrals accounted for $43 \%$ of all first treatments for cancer recorded on the CWT database (detection rate).

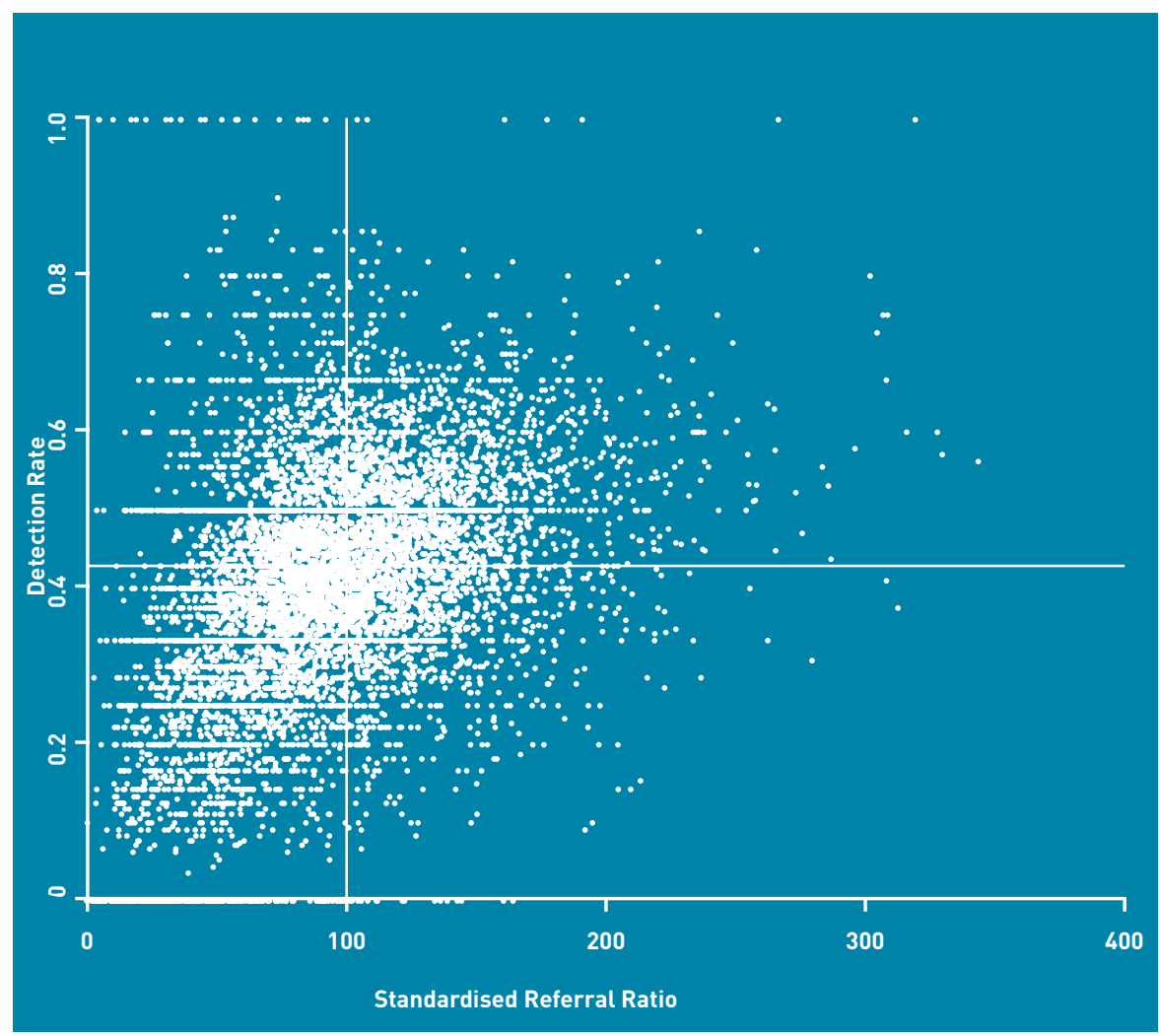




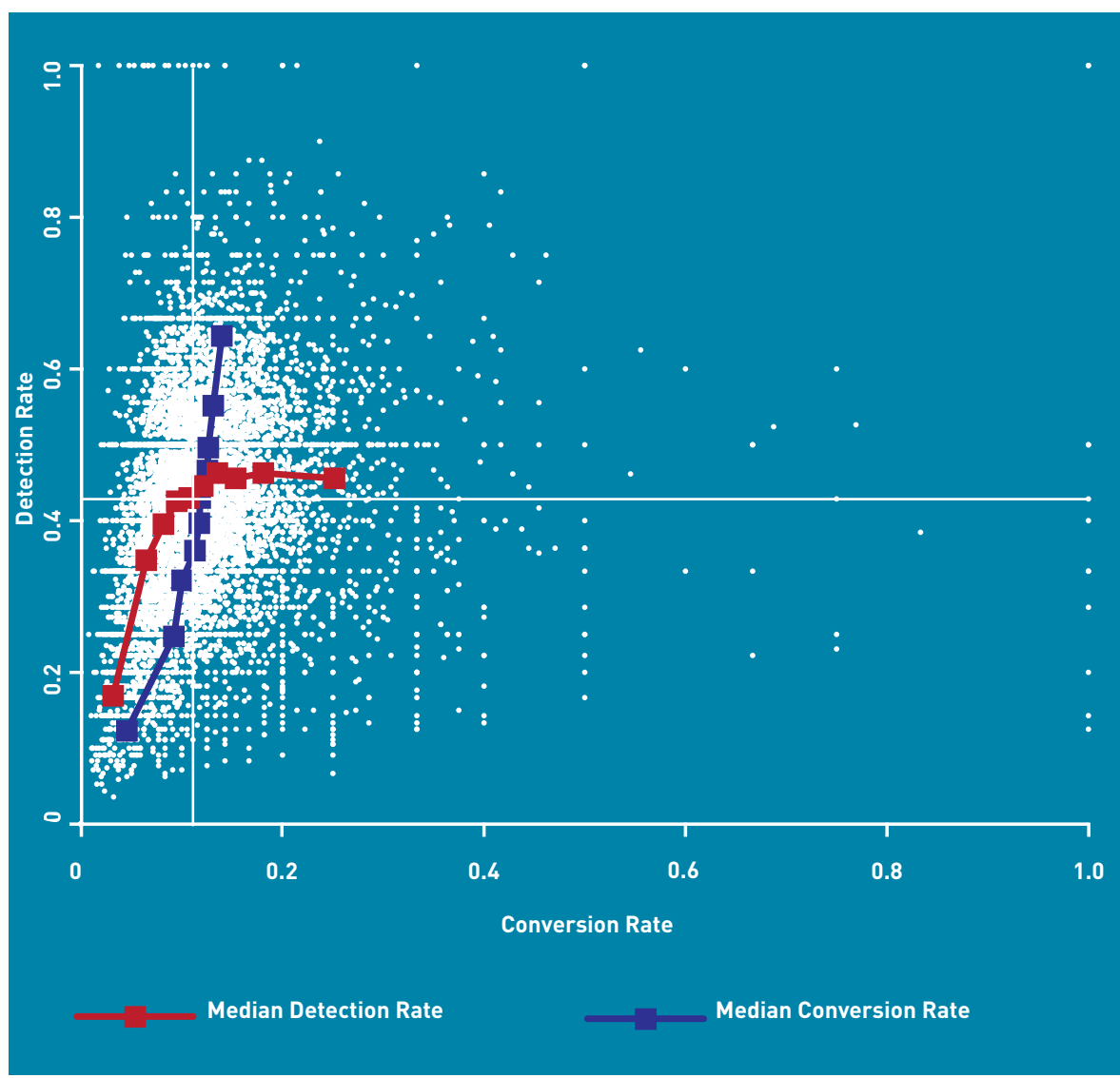

Figure 3. Correlation between conversion rate and detection rate (with lines plotting the median detection rate within deciles of conversion rate and the median conversion rate within deciles of detection rate).

After adjusting for age and sex, there was significant variation in standardised referral ratios, particularly by practice list size and SHA, but there was no significant deprivation gradient. Significantly lower conversion rates were found in the most deprived areas, for those aged $<65$ years and those practices with higher referral ratios. Lower detection rates were found in the most deprived areas, for those aged $<65$ years, those practices with low referral ratios and those practices with smaller list sizes.

\section{Correlations between the three measures}

An inverse relationship between standardised referral ratio and conversion rate was found; that is, those with higher $2 \mathrm{WW}$ referral ratios generally have lower conversion rates (correlation coefficient $-0.35, P<0.001$ ) (Figure 1).

A direct relationship between standardised referral ratio and detection rate was found; that is, those practices with higher referral ratios generally have higher detection rates (correlation coefficient 0.42 , $P<0.001$ ) (Figure 2).

Finally, a direct relationship between conversion and detection rates was found also; that is, those practices with higher conversion rates generally have higher detection rates and vice versa (correlation coefficient $0.37, P<0.001$ ) (Figure 3 ).

The correlations, between the standardised 2WW referral ratio and conversion rate, standardised $2 \mathrm{WW}$ referral ratio and detection rate, and conversion and detection rates remained significant when calculated for all patient and practice subgroups. (Table 2).

There was a statistically significant $(P<0.001)$ trend in detection rate, for deciles of practices based on conversion rate; the median detection rate increased from $17 \%$ for practices in the lowest decile of conversion rate to $45-46 \%$ for practices in the highest four deciles of conversion rate. There was also a statistically significant $(P<0.001)$ trend in conversion rate, for deciles of detection rate; the median conversion rate increasing from $4 \%$ to $14 \%$, for practices in the lowest to highest deciles of detection rate. In both cases, there was a marked difference between the lowest decile and all higher deciles. (Figure 3 )

\section{DISCUSSION}

\section{Summary}

There was a significant correlation between 2WW referral conversion and detection rates such that practices with higher conversion rates also tended to have higher detection rates and vice versa.

Everything else being equal, practices with low 2WW referral ratios would expect a high proportion of their referrals to be diagnosed with the disease (high conversion ratel compared with highreferring practices. Practices with low $2 \mathrm{WW}$ referral ratios would also expect a higher proportion of their patients to be diagnosed with cancer via other routes, such as following routine referrals or emergency presentation (low detection rate). These expected relationships have been borne out in the results of this study. They also imply that practices with high conversion rates would expect to have low detection rates, and vice versa. However, this study's results indicate that the opposite is true. Because the positive correlation observed between conversion rate and detection rate is significant across a wide range of patient and practice subgroups, it represents an intrinsic difference in diagnostic quality between practices; that is, a quality gradient.

As conversion rate increases, there is a ceiling effect in the increasing detection rate trend. Reasons for this include screen-detected cancers, patients not presenting to the GP with $2 \mathrm{WW}$-qualifying 
Table 2. Correlations between referral, conversion and detection rates, by various factors

\begin{tabular}{|c|c|c|c|c|c|c|}
\hline Factor & RR versus $\mathbf{C R}$ & $95 \% \mathrm{Cl}$ & RR versus $D R$ & $95 \% \mathrm{Cl}$ & CR versus DR & $95 \% \mathrm{Cl}$ \\
\hline Total & -0.35 & $(-0.37$ to -0.33$)$ & 0.42 & (0.40 to 0.44$)$ & 0.37 & (0.35 to 0.39 ) \\
\hline \multicolumn{7}{|l|}{ Age, year } \\
\hline$<65$ & -0.21 & $(-0.23$ to -0.19$)$ & 0.29 & $(0.27$ to 0.31$)$ & 0.57 & (0.55 to 0.58$)$ \\
\hline$\geq 65$ & -0.28 & $(-0.30$ to -0.26$)$ & 0.41 & (0.40 to 0.43$)$ & 0.44 & (0.42 to 0.45 ) \\
\hline \multicolumn{7}{|l|}{ Practice deprivation } \\
\hline Least deprived & -0.43 & $(-0.47$ to -0.38$)$ & 0.38 & $(0.34$ to 0.43$)$ & 0.35 & $(0.30$ to 0.40$)$ \\
\hline 2 & -0.45 & $(-0.49$ to -0.41$)$ & 0.41 & (0.36 to 0.45 ) & 0.28 & (0.23 to 0.33 ) \\
\hline 3 & -0.39 & $(-0.44$ to -0.35$)$ & 0.39 & (0.35 to 0.43$)$ & 0.34 & (0.29 to 0.38 ) \\
\hline 4 & -0.39 & $(-0.43$ to -0.35$)$ & 0.42 & $(0.38$ to 0.46$)$ & 0.35 & (0.30 to 0.39 ) \\
\hline Most deprived & -0.23 & $(-0.27$ to -0.19$)$ & 0.44 & (0.41 to 0.48$)$ & 0.46 & (0.43 to 0.50 ) \\
\hline \multicolumn{7}{|l|}{ SHA } \\
\hline North East & -0.56 & $(-0.63$ to -0.49$)$ & 0.37 & (0.28 to 0.45$)$ & 0.29 & (0.19 to 0.38 ) \\
\hline North West & -0.42 & $(-0.46$ to -0.37$)$ & 0.44 & $(0.40$ to 0.49$)$ & 0.30 & (0.25 to 0.35 ) \\
\hline Yorkshire \& the Humber & -0.43 & $(-0.49$ to -0.37$)$ & 0.43 & (0.37 to 0.48$)$ & 0.32 & (0.25 to 0.38 ) \\
\hline East Midlands & -0.41 & $(-0.48$ to -0.34$)$ & 0.44 & (0.37 to 0.50 ) & 0.29 & (0.21 to 0.36 ) \\
\hline West Midlands & -0.24 & $(-0.30$ to -0.18$)$ & 0.46 & $(0.41$ to 0.51$)$ & 0.45 & (0.40 to 0.50 ) \\
\hline East of England & -0.39 & $(-0.45$ to -0.33$)$ & 0.42 & (0.36 to 0.48$)$ & 0.37 & (0.31 to 0.43 ) \\
\hline London & -0.30 & $(-0.35$ to -0.25$)$ & 0.41 & (0.36 to 0.45$)$ & 0.46 & (0.42 to 0.50 ) \\
\hline South East Coast & -0.43 & $(-0.49$ to -0.36$)$ & 0.33 & (0.25 to 0.40$)$ & 0.33 & (0.26 to 0.40 ) \\
\hline South Central & -0.38 & $(-0.45$ to -0.30$)$ & 0.39 & (0.31 to 0.46$)$ & 0.34 & (0.26 to 0.42 ) \\
\hline South West & -0.49 & $(-0.54$ to -0.43$)$ & 0.40 & (0.33 to 0.46$)$ & 0.28 & (0.21 to 0.34 ) \\
\hline \multicolumn{7}{|l|}{$\mathrm{RR}^{\mathrm{a}}$} \\
\hline High & -0.32 & $(-0.36$ to -0.28$)$ & 0.14 & (0.09 to 0.18 ) & 0.53 & (0.50 to 0.56 ) \\
\hline Average & -0.15 & $(-0.18$ to -0.11$)$ & 0.11 & (0.08 to 0.15$)$ & 0.61 & (0.59 to 0.63 ) \\
\hline Low & -0.11 & $(-0.15$ to -0.08$)$ & 0.41 & (0.38 to 0.44 ) & 0.54 & (0.52 to 0.57$)$ \\
\hline \multicolumn{7}{|l|}{ Practice list size } \\
\hline$>6000$ & -0.45 & $(-0.48$ to -0.43$)$ & 0.36 & (0.33 to 0.39 ) & 0.31 & (0.28 to 0.34 ) \\
\hline $3001-6000$ & -0.34 & $(-0.37$ to -0.30$)$ & 0.42 & (0.39 to 0.45$)$ & 0.40 & (0.37 to 0.43 ) \\
\hline$\leq 3000$ & -0.22 & $(-0.27$ to -0.18$)$ & 0.43 & (0.39 to 0.47$)$ & 0.51 & (0.48 to 0.55$)$ \\
\hline
\end{tabular}

aHigh and low groups include practices with a standardised referral ratio which is significantly higher or lower than 100. The average group includes all other practices. $C R=$ conversion rate. $D R=$ detection rate. $R R=$ referral ratio. $S H A=$ strategic health authority.

alarm symptoms and diagnoses made as emergencies without prior presentation to the GP. However, as detection rate increases there is a continuing trend for increasing conversion rate, despite being skewed by the poor PPV of many cancer alarm symptoms, reflecting the accuracy with which the $2 \mathrm{WW}$ criteria are applied.

\section{Strengths and limitations}

On average a practice will have 27 new cancer diagnoses each year recorded in the CWT-Db. As a result, individual practice conversion rates and detection rates lack precision. However, this study's finding of a relationship between detection and conversion rates is based on an analysis of data for almost all of the practices in England, more than 8000 in total, and for 865000 referrals and 225000 cancers. The observed correlation between these two measures is therefore very unlikely to have occurred by chance and is not subject to bias in the selection of practices. Furthermore, the relationship is evident across all of the patient and practice subgroups investigated. Collection of the data used in this analysis is mandatory for all NHS provider trusts in England, meaning that these findings are nationally representative. It is also done according to agreed definitions and systematic data collection bias is therefore unlikely. However, as 2009 was the first year that cancer waiting times data were recorded according to a new system ${ }^{19}$ it is possible that the number of referrals may have been under-recorded in some hospitals, with some resulting inaccuracies in referral, conversion and detection rates for some practices.

Some patients diagnosed with cancer are not recorded in the CWT-Db; for example, those who die prior to treatment commencing or who receive treatment privately, ${ }_{1}^{20}$ or who are diagnosed outside the hospital setting. In 2009, the number of cases recorded on the CWT-Db was 15\% less than the number of cases lexcluding non melanoma skin cancer) registered by cancer registries, ${ }^{21}$ although there are some 
differences in the definitions used for these two data sources. In the current analysis, cases not recorded on the CWT-Db will not contribute to a practice's conversion or detection rate. However, is not expected to have a significant impact on the study's conclusions.

The number of cancers and number of referrals used to calculate the practice measures are based on slightly different cohorts of patients. Specifically, the number of $2 \mathrm{WW}$ referrals is taken as the number of cases first seen in the hospital receiving the referral in 2009, whereas the number of cancers is taken as the number of cases starting treatment in 2009. Although most patients first seen in 2009 will also have started treatment in that year, some patients starting treatment in 2009 will have been first seen in 2008 and some patients first seen in 2009 will not have started treatment until some time in 2010. This may have a small effect on the conversion and detection rates for some practices but the effect does not result in a systematic bias in any single direction.

Differential availability and use of direct access to diagnostic tests between practices and hospitals may have an effect on $2 \mathrm{WW}$ referral rates and resulting conversion and detection rates, particularly where use results in patients bypassing the $2 \mathrm{WW}$ pathway. For example, in some integrated respiratory medicine services, a patient suspected of having lung cancer following a GP referral for chest X-ray may be seen and diagnosed by a specialist without going through the 2WW pathway and will not contribute to that practice's 2WW detection rate. Similarly, patients diagnosed following referral from a national screening programme will also not contribute to their practice's detection rate.

Some cancers are more likely to be diagnosed as emergencies than others. ${ }^{5}$ The case mix of cancers in any one practice will therefore affect its referral, conversion and detection rates. However, in this study the correlations between measures remained consistent across all subgroups, and notably within all deprivation groups and geographical areas.

\section{Comparison with existing literature}

Referral rates from general practice have been extensively studied and a recent Scottish study has reported a sixfold variation between practices in referral rates for their equivalent of $2 \mathrm{WW}$ referral. ${ }^{22}$ A National Cancer Intelligence Network analysis of referral ratios for England has shown that $15 \%$ of practices made less than half the average number of $2 \mathrm{WW}$ referrals, while $10 \%$ made over $50 \%$ more than the average number of referrals. ${ }^{23}$ The $11 \%$ conversion rate reflects the low predictive value of cancer symptoms, even those regarded as alarm symptoms, ${ }^{24}$ while the $43 \%$ detection rate reflects the finding of a Danish study that around 50\% of patients with cancer do not present with alarm symptoms. ${ }^{25}$ The factors influencing referral, however, remain incompletely understood. A study using the General Practice Research Database found that morbidity explained $30 \%$ of total variation, whilst that attributable to practices was only $5 \% .{ }^{26}$ Socioeconomic status of the practice population explains about a quarter of the observed variation. ${ }^{27,28} \mathrm{~A}$ significant part of the variation remains unexplained and may relate to intrinsic psychological variables on the part of the GP and hospital supply factors. ${ }^{29}$ This study has highlighted that referral rates alone are a poor measure of quality of clinical care.

The current findings of a negative correlation between referral ratios and conversion rates and positive correlation between referral ratios and detection rates are consistent with earlier studies; for example of breast and gynaecological cancer 2WW referrals, where a downward trend in conversion rates was observed as referrals rose in the years after introduction of the urgent referral pathway. ${ }^{30,31}$

\section{Implications for research and practice}

A high conversion rate implies efficient use of the $2 \mathrm{WW}$ referral pathway. A high detection rate implies that fewer patients are being diagnosed by routes that are either slower, such as routine referrals, or as emergencies, a route associated with poorer outcomes. ${ }^{32} \mathrm{~A}$ high conversion rate together with a high detection rate (top right quadrant, Figure 3) therefore constitutes an indicator of good clinical practice and the positive correlation found across all practices represents a quality gradient in cancer referral practice. Furthermore, practices in the top left quadrant llow conversion, high detection) may be overusing the $2 \mathrm{WW}$ referral pathway, while those in the bottom right quadrant (high conversion, low detection) may not be using it enough. Those practices in the bottom left quadrant (low conversion, low detection) may be poor at case selection, implying poor clinical practice. These interpretations can help practices to interpret their practice cancer profiles, can inform a more meaningful dialogue between primary care, secondary care and cancer networks and allows them 
to measure improvement over time.

The Quality and Outcomes Framework (QOF) contains only two indicators for cancer care, neither of which relate to earlier diagnosis. These findings show that two separate, readily available measures of diagnostic performance (conversion rate and detection ratel are correlated in such a way as to offer a means of distinguishing good and poor referral practice, and could serve as the basis for a QOF indicator. Further modelling is required, however, to investigate the feasibility of developing a robust indicator based on these two measures which takes into account both systematic and random variation between practices.

These findings can inform QIPP initiatives, notably those intended to reduce inappropriate referrals. For cancer, $2 \mathrm{WW}$ referral rate alone is not a measure of quality, and the relationship between conversion and detection rates is more important. Similar relationships may be evident in other clinical areas. For example, practice quality of care loverall clinical QOF scorel has already been shown to be associated with risk of admission for angina. ${ }^{33}$ The analysis of referrals to rapid access chest pain clinics using this study's approach may allow new insights into quality of cardiovascular care.

Practice cancer profiles were provided to practices for the first time in 2010 and, by repeating this analysis in 2011, their impact on conversion and detection should be apparent. Further detailed study of those practices that achieve high conversion and high detection rates may give insights into the direction for future quality improvement initiatives for cancer diagnosis in general practice. Conversely, the use of cancerspecific audit and significant event analysis may help practices with low conversion and detection rates to identify where they may have scope for improvement. ${ }^{34}$

There remains a need for more detailed analyses of these data, to investigate possible explanations for why those practices with the lowest conversion rates also tend to have much lower detection rates (and vice-versa) and to determine whether the quality gradient is consistent across individual cancer sites and how it impacts on patient outcomes such as survival. The routine collection of this data also allows the possibility of longitudinal research studies of the impact of quality improvement initiatives in general practice. 


\section{REFERENCES}

1. Department of Health. HSC2000/013 Referral Guidelines for suspected cancer. London: DoH, 2000

2. Department of Health. Cancer reform strategy. London: DoH, 2007.

3. Department of Health. Improving outcomes: a strategy for cancer. London: DoH, 2001.

4. Cancer Research UK. About the National Awareness and Early Diagnosis Initiative. http://info.cancerresearchuk.org/spotcancerearly/naedi/AboutNAEDI/ laccessed 19 Jul 2012).

5. National Cancer Intelligence Network. Routes to diagnosis - NCIN data briefing. London: NCIN. http://www.ncin.org.uk/publications/data_briefings/routes_to diagnosis.aspx (accessed 19 Jul 2012).

6. National Audit Office. Delivering the cancer reform strategy. London: The Stationery Office, 2010.

7. Jones R, Rubin G, Hungin P. Is the two week wait for cancer working? BMJ 2001 . 322(7302): 1555-1556.

8. Lewis R, Collins R, Flynn A, et al. A systematic review of cancer waiting time audits. Qual Saf Health Care 2005; 14: 62-66.

9. National Institute for Health and Clinical Excellence. Search the NICE referral advice' recommendations database. London: NICE. http://www.nice.org.uk/ usingguidance/referraladvice/search.jsp (accessed 19 Jul 2012).

10. Department of Health. The NHS quality, innovation, productivity and prevention challenge: an introduction for clinicians. London: DoH, 2010.

11. Prades J, Espinas JA, Font R, et al. Implementing a cancer fast-track programme between primary and secondary care in Catalonia (Spain): a mixed methods study. Br J Cancer 2011; 105(6): 753-759.

12. Olesen F, Hansen RP, Vedsted P. Delay in diagnosis: the experience in Denmark Br J Cancer 2009; 101(Suppl 2): S5-S8.

13. Public Accounts Committee. 24th Report: delivering the cancer reform strategy. London: House of Commons, 2011.

14. National Cancer Intelligence Network. General practice profiles for cancer http://ncin.org.uk/cancer_information_tools/profiles/gp_profiles.aspx laccessed 6 Aug 2012)

15. National Cancer Intelligence Network. General practice profiles for cancer Metadata for profile indicators. Version 1.2. London: NCIN, 2010. http://ncin.org. uk/view.aspx?rid=90 (accessed 19 Jul 2012).

16. National General Practice Profiles. FAQs for National General Practice Profiles http://www.apho.org.uk/resource/item.aspx?RID=96895 laccessed 6 Aug 2012).

17. Cuzick J. A Wilcoxon-type Test for Trend. Stat Med 1985; 4(1): 87-90.

18. The Information Centre. The Quality and Outcomes Framework 2010/11. http:// wnw.ic.nhs.uk/qof laccessed 19 Jul 2012)

19. Richards M. Dear colleague letter: going further on cancer waits. London:
Department of Health, 2008

20. National Cancer Intelligence Network and National Cancer Action Team. Cancer waiting times (CWTS). A guide. Version 7.0. London: NCIN. http://www.nwlcn.nhs. uk/Downloads/Cancer\%2OIntelligence/Going\%20Forward\%20on\%20Cancer\%20 Waits\%20A\%20Guide\%20Version\%207.0.pdf (accessed 19 Jul 2012).

21. Office for National Statistics. Cancer statistics registrations: registrations of cancer diagnosed in 2009, England. Series MB1 40. Office for National Statistics, 2011.

22. Baughan P, Keatings J, O'Neill B. Urgent suspected cancer referrals from general practice: audit of compliance with guidelines and referral outcomes. $\mathrm{Br}$ J Gen Pract 2011; DOI: 10.3399/bjgp11×606591

23. National Cancer Intelligence Network. Urgent GP referral rates for suspected cancer. London: NCIN, 2011. http://www.ncin.org.uk/publications/data_briefings/ gp_referral_rates.aspx laccessed 19 Jul 2012).

24. Shapley M, Mansell G, Jordan JL, Jordan KP. Positive predictive values of $\geq 5 \%$ in primary care for cancer: systematic review. Br J Gen Pract 2010; DOI: 10.3399/bjgp10X515412

25. Nielsen TN, Hansen RP, Vedsted P. Symptom presentation in cancer patients in general practice. Ugeskr Laeger 2010; 172(41): 2827-2831.

26. O'Sullivan C, Omar RZ, Ambler G, Majeed A. Case-mix and variation in specialist referrals to general practice. Br J Gen Pract 2005; 55(516): 529-533.

27. Sorensen $\mathrm{TH}$, Olsen $\mathrm{KR}$, Vedsted $\mathrm{P}$. Association between general practice referral rates and the patient's socio-economic status and access to specialised health care: a population based nationwide study. Health Policy 2009; 92(2-3): 180-186

28. Hippisley-Cox J, Hardy C, Pringle M, et al. Effect of deprivation on general practitioners' referral rates. BMJ 1997; 315(7112): 882-883.

29. O'Donnell C. Variation in GP referral rates: what can we learn from the literature? Fam Pract 2000; 17(6): 462-471.

30. Potter S, Govindarajulu S, Shere M, et al. Referral patterns, cancer diagnoses and waiting times after introduction of the two week wait rule for breast cancer: prospective audit study. BMJ 2007; 335(7614): 288

31. Morrison J, Gillespie S, MacKenzie IZ. Two week wait standards for suspected gynaecological malignancy. On target, but missing the point? J Br Menopause Soc 2003; 9(4): 170-172.

32. McArdle CS, Hole DJ. Emergency presentation of colorectal cancer is associated with poor 5-year survival. Br J Surg 2004; 91(5): 605-609.

33. Purdy S, Griffin T, Salisbury C, Sharp D. Emergency admissions for coronary heart disease: a cross sectional study of general practice, population and hospital factors in England. Public Health 2011; 125(1): 46-54.

34. RCGP national audit of cancer diagnosis in primary care 2011. Durham: Durham University. http://uww.dur.ac.uk/school.health/erdu/cancer_audit/ laccessed 19 Jul 2012) 